\title{
Investigation of Stick-Slip Vibration in a Commercial Vehicle Brake Assembly
}

\author{
Naveed Ashraf \\ School of Engineering, Manchester Metropolitan University, Manchester, M1 5GD, UK.
}

David Bryant and John D. Fieldhouse

School of Engineering, University of Bradford, Bradford, BD7 1DP, UK.

(Received 4 December 2014; accepted 3 May 2016)

There are several types of disc brake instabilities associated with the brake systems; however, they are usually classified into two main categories depending on the frequency range: brake groan $0-300 \mathrm{~Hz}$ and brake squeal $1-$ $16 \mathrm{kHz}$. The groan is associated with the stick-slip motion while the squeal is associated with the modal coupling. This paper presents a detailed analysis of low frequency noise $(0-300 \mathrm{~Hz})$ in a commercial vehicle trailer disc brake as a result of stick-slip vibration. A range of experimental techniques are used to understand the characteristic behaviour of the caliper and the brake pads during braking events on a laboratory test rig. The analysed brake system comprised a full disc brake assembly and the trailer suspension system with a beam axle. Laser-based optical displacement sensors were used to investigate the deformation of the caliper body and the brake pads during a braking application. The contact pressure distribution at the disc/pad interfaces were also measured to gain more insight into the contact profile of the pad surfaces. Results revealed that the stick-slip phenomenon, in this study, was a result of the combination of the deformation of the caliper and the friction material formulation of the brake pads. In addition, it was observed through the testing of two different sets of pads that a low compression modulus would help to reduce the stick-slip phenomenon.

\section{INTRODUCTION}

Brake noise and vibration continues to be a major concern for the automotive industry. An assortment of techniques and theories is utilised, within both industry and research institutes, to eliminate or diminish the noise and vibration of the brake assembly. However, there is still lack of any universal model or theory which can explain the behaviour of a noisy brake system in general. ${ }^{1}$ There are several types of brake instabilities associated with disc brake assemblies; however, in this paper, the focus was upon the mechanically driven instability of stickslip vibration. This is a low frequency noise, typically less than $200 \mathrm{~Hz}$, which occurs at low speed and is initiated by the "stick-slip" motion between the disc/pad interfaces. ${ }^{2,3}$ Stickslip phenomenon at the disc/pad interfaces is associated with the disc speed and the difference between the static and dynamic coefficients of friction of the disc and friction material. It is known that stick-slip may be the result of the disc/pad interface friction characteristics with the dynamic friction coefficient being less than the static friction coefficient (stiction) and the negative slope of the /speed graph. The resulting, so called, "stick-slip" instability is highly dependent on the "system" inertias (masses) and "system" stiffness which in turn includes both the suspension and caliper mounting stiffness. ${ }^{4}$ Jang, et al., ${ }^{5}$ suggested a number of methods to eradicate the vibration due to stick-slip behaviour in a brake disc assembly. They emphasised that the propensity of vibration can be reduced by modifying the mechanical assembly, typically, by increasing the damping of the brake assembly and increasing both the inertia of the body, the caliper stiffness and its mounting stiffness. The other significant recommendation was to diminish the oscillatory vibration at the disc/pad interfaces by changing the formulation of the friction material to develop a more uni- form and controlled transfer layer on the disc and pad surfaces. Fuadi, et al., ${ }^{6}$ suggested that the brake assembly is more prone to "groan" noise when the value of stiffness ratio (the ratio of the contact stiffness to structural stiffness) is high. They established that the stick-slip vibration phenomenon can be avoided if the difference between the static and dynamic coefficients of friction is low. Kim, et al., ${ }^{7}$ examined the friction characteristics of abrasive particles using silicon carbide, zircon, quartz, and magnesia. For microscopic understanding of friction and wear, they performed single-particle scratch tests followed by scratch tests with multiple particles. The results showed that the fracture toughness of the abrasives played a crucial role in determining the friction level, wear debris formation, and stick-slip. The friction material with silicon carbide exhibited a considerable stick-slip behaviour, indicating a possible high propensity of noise occurrence during brake applications. On the other hand, the quartz and magnesia particles with low fracture toughness showed relatively small stick-slip amplitudes. $\mathrm{Xie}$, et al., ${ }^{8}$ investigated the propensity of brake moan noise on basis of damping ratio of a dynamic brake system model. By using the finite element model and experimental studies, they examined the effects of the brake pad taper wear on brake moan noise. The results showed that the brake pad taper wear is a main factor for generating the brake moan noise. They established that the negative damping ratios and the tendency of brake moan increased as the pad wore down. The results indicated that the effect of friction coefficients played a significant role on the generation of brake noise, and the instability of the brake system increased with the higher value of friction coefficient. Kim, et al., ${ }^{9}$ replicated the moan noise during the vehicle's operating test and identified that the resonance of the beam axle module, due to the exciting force of the brake system, is the main cause of moan noise. They conducted both 
coherence and transfer path analysis to identify how the vibrations from the beam axle module were related to moan noise.

Although much work has been carried out to understand the primary cause of stick-slip vibration in brake assemblies, it still remains a problem and thus needs to be examined in more detail. It is recognised that stick-slip vibration involves the rigid body oscillation of the full brake assembly at the axle; this assembly includes the suspension, brake pads, disc, caliper, and knuckle. It is therefore classified as a low frequency "groan" noise which is historically difficult to replicate in a brake laboratory. ${ }^{10}$ Much of the previous work, carried out by other authors, has been focused on understanding the behaviour of stick-slip vibration by either developing a simple mathematical model or by investigating a simple brake system without an associated suspension system within a controlled environment. The brake assembly considered in this work consisted of a full trailer axle assembly with the suspension mechanism mounted upside down fixed securely to the ground, which in this case represents the trailer body. In order to understand the characteristic behaviour of stick-slip vibration, optical displacement sensors were used to measure the deformation of brake components during braking events. In addition, the contact pressure distribution of disc/pad interfaces were measured to examine the contact profile of the pad surfaces. Furthermore, a number of parametric studies were examined to reduce the propensity of audible noise and vibration of the brake assembly.

\section{EXPERIMENTAL SET-UP}

A test rig was designed and constructed to investigate the stick-slip vibration in the disc brake assembly of a commercial vehicle trailer as shown in Fig. 1. The brake assembly under consideration was part of the trailer beam axle with air actuation brakes; there were two disc rotors with caliper mounted to the beam axle on each end. A two-piston sliding-type caliper was installed with a ventilated disc of $430 \mathrm{~mm}$ diameter (see Table 1 for detailed description of brake assembly). The axle was inverted and mounted securely to the ground by the suspension mechanism comprising the damper and the air spring. It was noted that this would influence the forces on the assembly; however, in practice it was found to have no significant effect on noise/vibration generation. Only one disc was driven on the test rig, so the disc rotor on the un- driven side of the axle was securely clamped to a rigid base plate. The driven disc was mounted on a substantial shaft held in taper roller bearings and loaded to give zero axial float. The brake disc was driven through a flexible coupling direct from a $45 \mathrm{~kW}$, $2440 \mathrm{rpm}$ 3-phase A.C. motor through a 30:1 worm-wheel reducer. Flexible coupling was used to accommodate angular, radial and parallel misalignment between the shaft, flange, and the gearbox, thus avoiding externally induced forces being imposed onto the brake head. Disc speed was controlled using a "vector" controller that provided reliable constant variable speed starting from $1.0 \mathrm{rev} / \mathrm{min}$ up to a maximum speed of $80 \mathrm{rev} / \mathrm{min}$.

Disc temperature was measured using a non-contact laser infrared thermometer with a range of 0 to $250^{\circ} \mathrm{C}$. A condensingtype microphone was placed at distance of $100 \mathrm{~mm}$ from the disc face and $500 \mathrm{~mm}$ above and perpendicular to the centreline of the disc as identified in SAE procedure J2521. FFT spectrum analyser was used to identify the generated noise frequencies.

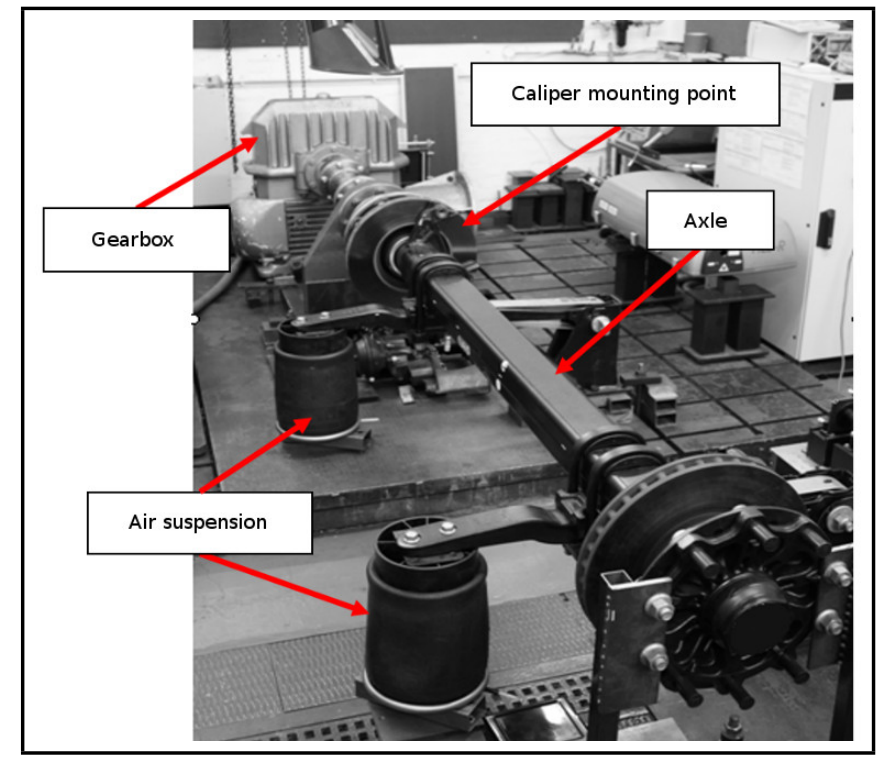

Figure 1. General view of the test rig with trailer axle mounted to the floor.

Table 1. Detailed description of Brake assembly

\begin{tabular}{||c|c|}
\hline \multicolumn{2}{|c|}{ Brake Disc } \\
\hline Diameter $(\mathrm{mm})$ & 430 \\
\hline Effective radius $(\mathrm{mm})$ & 171.5 \\
\hline Thickness $(\mathrm{mm})$ & 45 \\
\hline \multicolumn{2}{|c|}{ Brake Pads } \\
\hline Length $(\mathrm{mm})$ & 210.7 (backplate) \\
\hline Width $(\mathrm{mm})$ & 84 \\
\hline Thickness $(\mathrm{mm})$ & 30 mm including 9 mm backplate \\
\hline Surface area $\left(\mathrm{cm}^{2}\right)$ & $2 \times 148$ \\
\hline Pad A & Pad B \\
\hline \multicolumn{2}{|c|}{ Compressibility at $8 \mathrm{MPa}(\mu \mathrm{m})$} \\
\hline Compressive Stiffness $(\mathrm{GPa})$ \\
\hline \multicolumn{2}{|c|}{243} \\
\hline Brake Caliper \\
\hline Type & Sliding caliper brake (pneumatic) \\
\hline No of pistons & 2 pistons \\
\hline
\end{tabular}

\section{EXPERIMENTAL PROCEDURE}

The "stick-slip" vibration characteristic/propensity was recorded by measuring noise levels and frequencies. Initially brake pads with high compression modulus ( $\mathrm{Pad} \mathrm{A})$ were used to examine the stick-slip phenomenon. A temperature/pressure noise matrix test was conducted to determine the noise propensity of the brake system during the generation of stick-slip vibrations. All brake pads were fully "bedded in" with the brake disc before performing any noise tests to ensure consistent and reliable results. The bedding-in procedure involved performing short drag braking events at different speeds (1080rev/min) and pressures (between 1-5 bar air actuation pressure) whilst allowing the brake disc temperature to steadily increase to $250^{\circ} \mathrm{C}$. Temperature rise during each braking event was in the region of $10-20^{\circ} \mathrm{C}$ and the disc temperature at the beginning of the "bedding" procedure was $20^{\circ} \mathrm{C}$. Once the disc temperature of $250^{\circ} \mathrm{C}$ had been reached, the disc was allowed to cool down to $20^{\circ} \mathrm{C}$. Following this process, the brake was examined visually and the disc and pad surfaces were inspected to ensure that full contact between disc and pad had been achieved (a clean and uniform rubbing path) and, by observation, that the surface transfer was complete about the disc.

For the experimental measurements, the temperature of the disc was raised, through braking applications, to over $250^{\circ} \mathrm{C}$ 


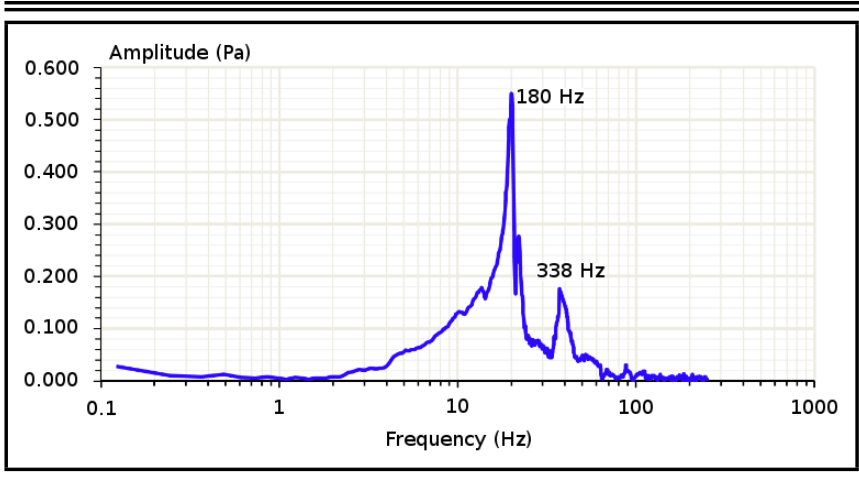

Figure 2. Frequency spectrum of the recorded noise using microphone (Pad A).

Table 2. Test criteria and brake noise characteristics.

\begin{tabular}{|c|c|c|c|c|}
\hline $\begin{array}{c}\text { Applied } \\
\text { Pressure } \\
\text { (bar) }\end{array}$ & $\begin{array}{c}\text { Disc Speed } \\
(\text { rev/min) }\end{array}$ & $\begin{array}{c}\text { Temperature } \\
\left({ }^{\circ} \mathbf{C}\right)\end{array}$ & $\begin{array}{c}\text { Frequency } \\
(\mathbf{H z})\end{array}$ & $\begin{array}{c}\text { Type of } \\
\text { Noise }\end{array}$ \\
\hline 2.5 & 14 & 150 & 180 & Stick-slip \\
\hline
\end{tabular}

and the brake speed was set at $14 \mathrm{rev} / \mathrm{min}$. As the disc temperature decayed due to cooling the brake pressure gradually increased and decreased; any noticeable noise frequencies were recorded together with the disc temperature and the brake line pressure. The test characteristics that generated the low frequency noise are shown in Table 2 and Fig. 2.

\section{RESULTS}

Preliminary noise tests revealed that whenever stick-slip noise occurred, the inboard pad showed a trailing series of successive pad imprints ("chatter" marks) on the surface of the disc, which was indicative of the stick-slip phenomenon. However there was no evidence of pad imprints on the outboard surface of the disc; this unusual behaviour of the inboard pad may have been responsible for the instability within the brake assembly. It was also evident from noise assessment tests that the part-worn pads tended to generate stick-slip noise more often than freshly bedded pads.

Laser-based optical displacement sensors manufactured by Micro-Epsilon (model no: ILD1300-20) were used to investigate the deformation of the brake components including the caliper and the pads during braking events. The measuring range of these sensors is between $20-200 \mathrm{~mm}$ with the dynamic resolution of $100 \mu \mathrm{m}$, a measuring rate of $750 \mathrm{~Hz}$ and the operating temperature range is between $0-50^{\circ} \mathrm{C}$. A Labview-based programme with integrated data acquisition was developed to measure the displacement of brake components during testing.

It was apparent from the frequency spectrum of the recorded noise that the brake assembly tended to generate a low frequency noise at $180 \mathrm{~Hz}$ as illustrated in Fig. 2 - the same frequency associated with the occurrence of vibration from the stick-slip phenomenon as confirmed by the sponsor company. Experimental modal testing, under constrained condition, was then performed to measure the natural frequencies of the beam axle to determine if these were being excited by the stick-slip vibration. A force transducer was attached to the axle using a threaded stud mounted in a tapped hole. The axle was excited using a LDS permanent magnet shaker (model no: V406), with frequency range from 5 to $9000 \mathrm{~Hz}$, which was mechanically coupled to the force transducer using a "stinger" as exhibited

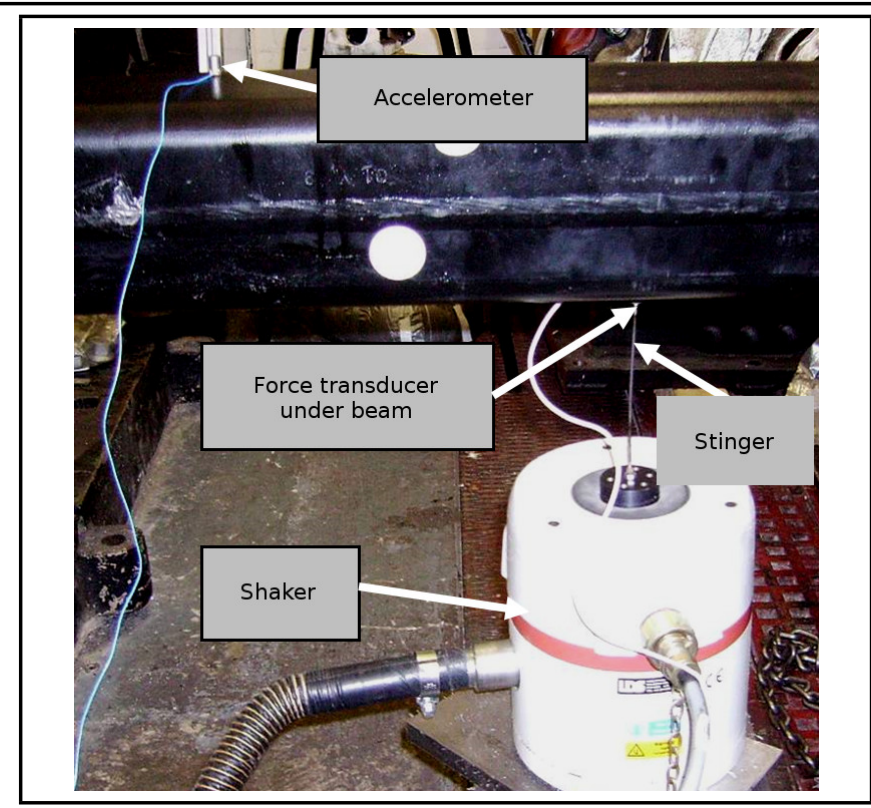

Figure 3. Set-up for beam FRF investigation with the shaker exciting the beam axle.

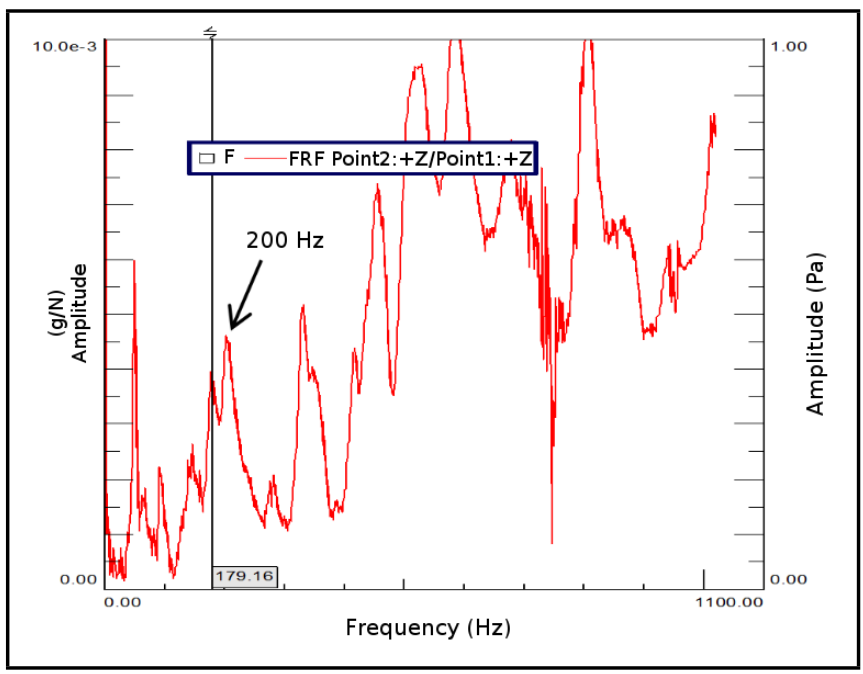

Figure 4. FRF results below $1264 \mathrm{~Hz}$ with local peak at $179 \mathrm{~Hz}$ indicated. The second higher frequency peak to the right is $200 \mathrm{~Hz}$.

in Fig. 3. An accelerometer (mounted to the axle) was connected to the data acquisition system, together with the force transducer; the results from these were used to provide the frequency response. The response from the accelerometer indicated that the dominant frequencies were in the region of $179 \mathrm{~Hz}$ as shown in Fig. 4, which correlated well with the noise measurements. There was a second higher frequency of $200 \mathrm{~Hz}$, which was also in the region of the reported instabilities. Vehicle tests, performed by the sponsor of this project, revealed that this particular brake was experiencing a low frequency noise between $180-190 \mathrm{~Hz}$ being transmitted to the whole trailer chassis. The shaker testing identified that the beam axle may be a possible transfer path with two natural frequencies being close to this range.

It was recognised from published literature ${ }^{3,4}$ that low frequency noise associated with stick- slip vibration is highly dependent on the movement of the caliper as well as "twisting" of the caliper around its centre, which causes the pads to "dig-in" to the disc. It was therefore essential to examine the dynamic deformation of both the caliper and the brake pads during brak- 


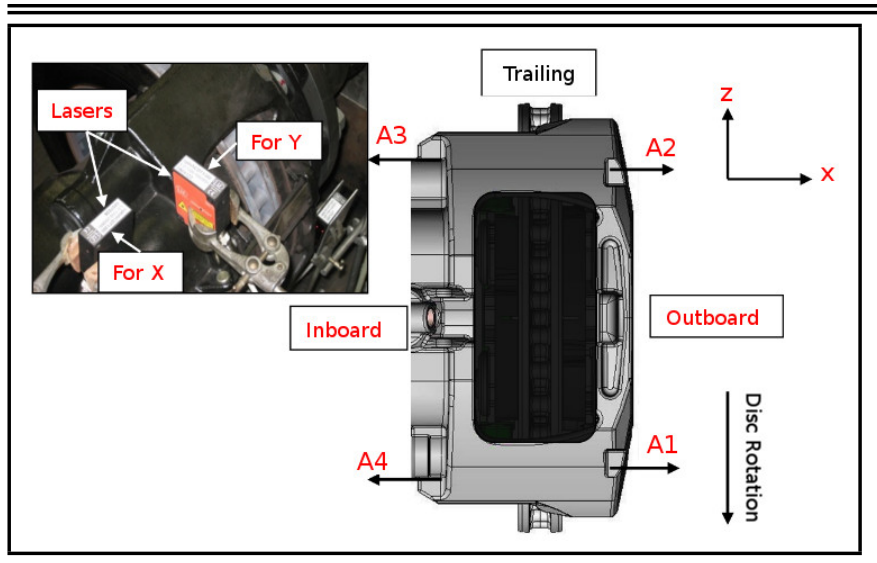

Figure 5. Arrangement of optical sensors at points A1, A2, A3, and A4 in the $\mathrm{X}, \mathrm{Y}$, and $\mathrm{Z}$ axis(Note: $\mathrm{Y}$ axis is negative into the paper).

ing events.

\subsection{Displacement Measurements of Brake Components}

\subsubsection{Caliper elastic deformation measurement}

Minimising the brake caliper deflection has always been a target for brake designers. This was recognised by Tirovic, et al., ${ }^{11}$ who created a design program that considered caliper loading during a range of braking scenarios and provided material necessary to the caliper only to provide structural integrity. This approach provided an appropriately robust structure but a light caliper with little redundant material. Excessive deflection of the caliper can lead to tapered pad wear and irregular contact area of the friction material, subsequently resulting in stick-slip vibration in a brake system. ${ }^{12}$ Therefore, for this study, the dynamic deformation of the caliper body due to braking forces was measured at various points on the caliper as shown in Fig. 5. At each setting the absolute displacements were measured in three axes; $x$ (axial), y (radial), and $\mathrm{z}$ (tangential). The sensors were placed at distance of $50 \mathrm{~mm}$ from the caliper body and brake pressure was applied to observe the behaviour of the caliper body under load.

The measurements were initially taken in the X-direction of the caliper (axial). The tests included static measurements of the caliper deflection (no disc rotation but full brake torsional loading) to provide a system benchmark. Once the static characteristic behaviour of the caliper was established, deformation was measured under dynamic conditions.

It was established from the results shown in Fig. 6 that the axial deflection of the caliper was larger at the trailing edge than at the leading edge. The trailing edge of the caliper moved approximately $1.9 \mathrm{~mm}$ inboard; however, the deformation towards the leading edge of the caliper was negligible.

Radial and tangential displacements of the caliper were also measured using $\mathrm{Y}$ and $\mathrm{Z}$ laser transducers, respectively, as shown in Figs. 7(a) and (b) and their maximum values are presented in Table 3. It should be noted that all measurement points experienced positive displacement in the $\mathrm{z}$ axis (in the braking direction) and that the inferred negative $\mathrm{z}$ measurements in Fig. 8 are due to reversed orientation of the transducers A1 and A4 than with those positioned at A2 and A3. It was also observed that the trailing edge of the caliper was pulled towards the centre (i.e. in the -ve radial direction) of the disc and that the leading edge of the caliper was pushed out away from the centre of the disc as shown in Fig. 8.

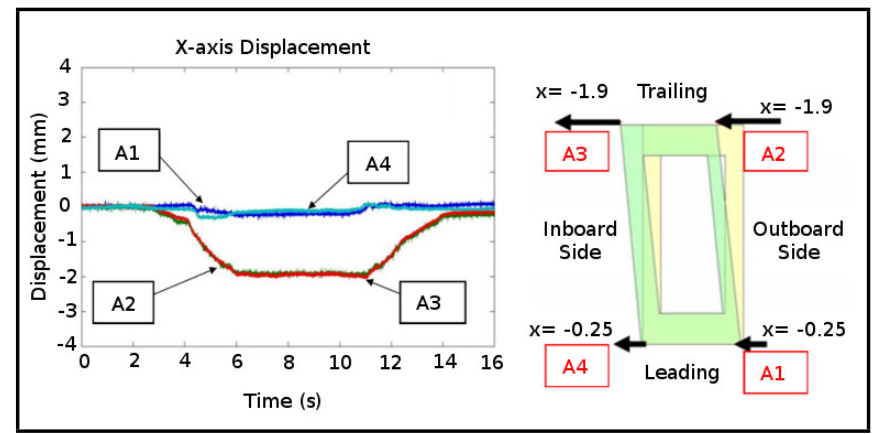

Figure 6. Caliper displacement in the X-axis: Raw measurements (left) and graphical representation (right)

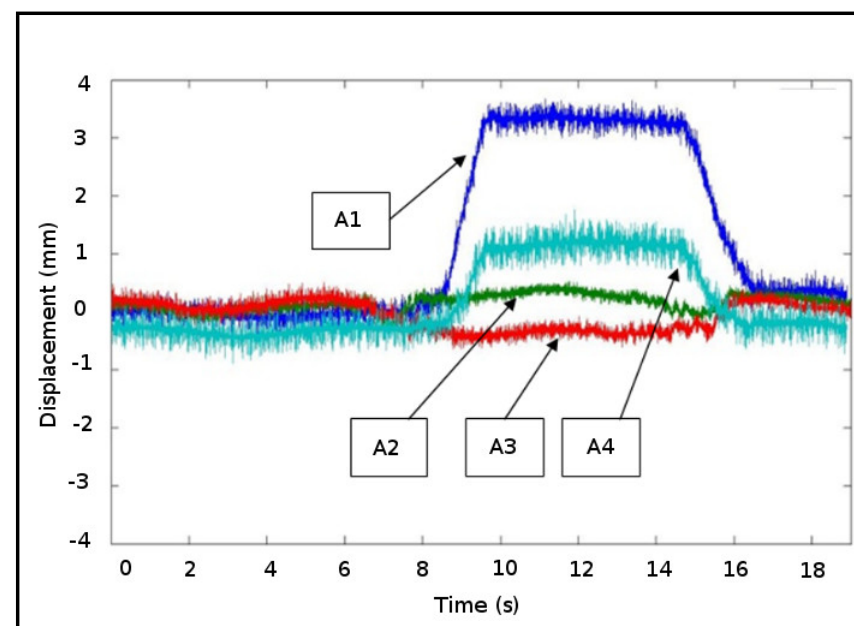

(a) Y-axis Displacement

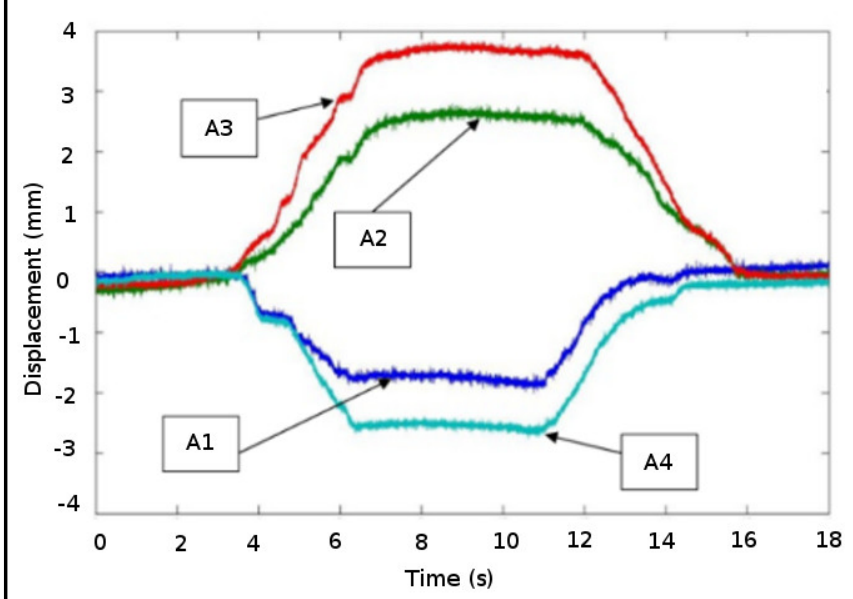

(b) Z-axis Displacement

Figure 7. Caliper displacement radially in the Y-axis (a) and tangentially in the Z-axis (b).

\subsubsection{Displacement measurement of the brake pads}

The elastic deformation of the outboard and inboard pads was studied to determine their dynamic behaviour during braking events. All measurements were taken in the $\mathrm{X}$ direction (axial) with the disc rotating at constant speed of $14 \mathrm{rev} / \mathrm{min}$.

It was noted from the displacement results that both the inboard and outboard pad displaced in the same direction. It was found that the outboard pad shifted with the caliper body towards the disc surface, tilting more at the trailing edge, whereas there was only a small movement at the leading edge. Whilst the inboard pad moved towards the disc by $0.5 \mathrm{~mm}$ at 
Table 3. Radial and tangential displacement of the caliper including calculated angular displacements.

\begin{tabular}{||c|c|c|c|}
\hline Point on caliper & $\begin{array}{c}\text { Angle with horizontal } \\
\text { (anticlockwise = +ve) }\end{array}$ & $\begin{array}{c}\text { Radial displacement (Y axis } \\
\text { - away from centre = +ve) mm }\end{array}$ & $\begin{array}{c}\text { Tangential displacement (Z axis } \\
\text { - anticlockwise, looking from inboard = +ve) mm }\end{array}$ \\
\hline A1 (outboard bottom) & $-18^{\circ}$ & 0.57 & 3.70 \\
\hline A2 (outboard top) & $58^{\circ}$ & -1.01 & 2.43 \\
\hline A3 (inboard top) & $69^{\circ}$ & -1.66 & 3.33 \\
\hline A4 (inboard bottom) & $-29^{\circ}$ & 1.60 & 2.26 \\
\hline
\end{tabular}

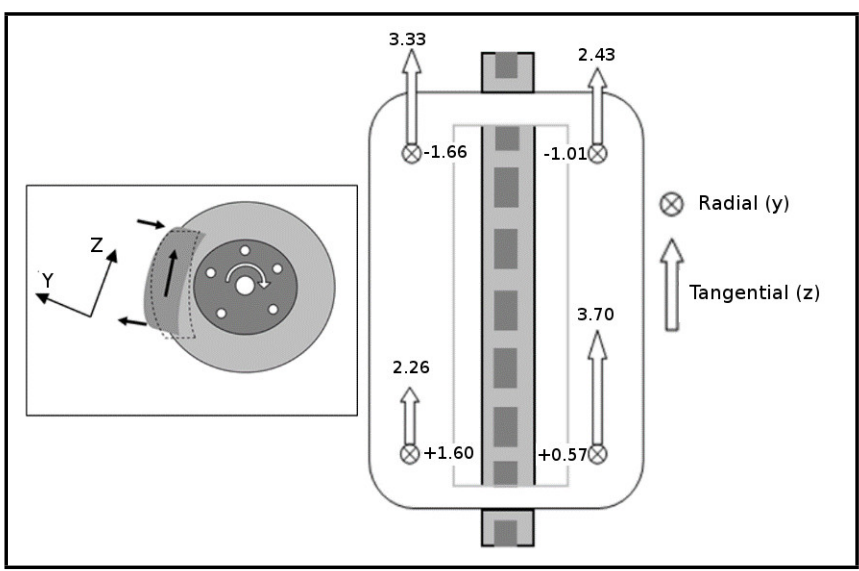

Figure 8. Graphical representation of caliper deflection showing the outboard view (left) and maximum caliper radial and tangential displacements (right).

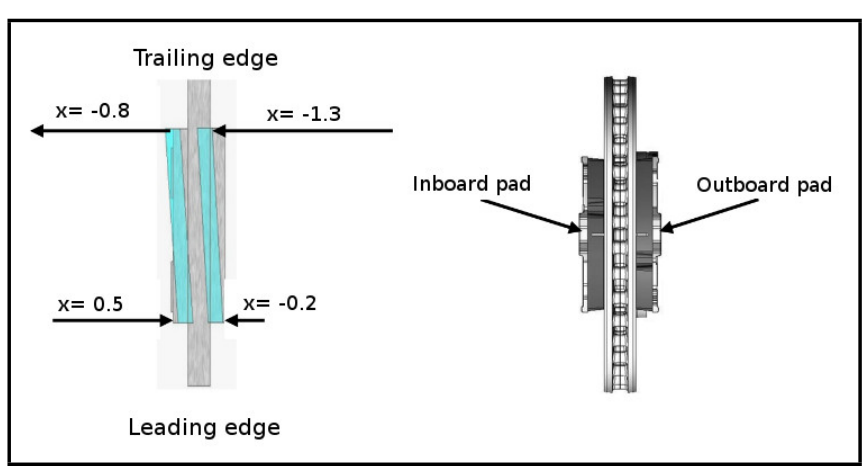

Figure 9. Schematic diagram showing the magnitude and direction of brake pad displacement in the X-direction (axial) - dynamic tests.

the leading edge causing the pad to plunge into the disc, the trailing edge of the pad moved away from the disc by $0.8 \mathrm{~mm}$, resulting in no contact with the disc surface as shown in Fig. 9. A dynamic frequency analysis of both pads was also conducted to determine the low frequency noise that was associated with the stick-slip vibration as displayed in Figs. 10(a) and (b). A "burst" part of the displacement signal was taken to perform a spectral analysis, from which it was observed that the outboard pad was vibrating at a frequency of $225 \mathrm{~Hz}$, whereas the inboard pad was vibrating at a frequency of $200 \mathrm{~Hz}$. At the same time, it was noted that the inboard pad amplitude was higher than the outboard pad. Without further evidence, it is suggested that there is an energy balance between the two pads - one having higher frequency but lower amplitude whilst the other having lower frequency but higher amplitude. This observation will be the subject of further study. In general, these results compare favourably with the dynamic tests which showed that the noise frequency generated during stick-slip was $180 \mathrm{~Hz}$.

\subsection{Contact Pressure Distribution Analysis}

In order to explain the behaviour of both the outboard and inboard pads, the contact profile of the pad surfaces was ex-

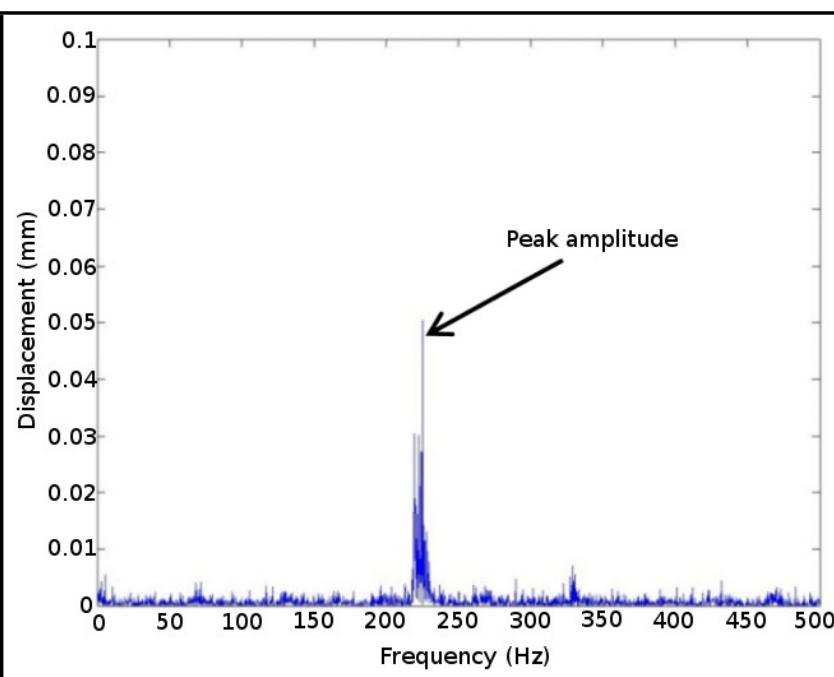

(a) Outboard Pad

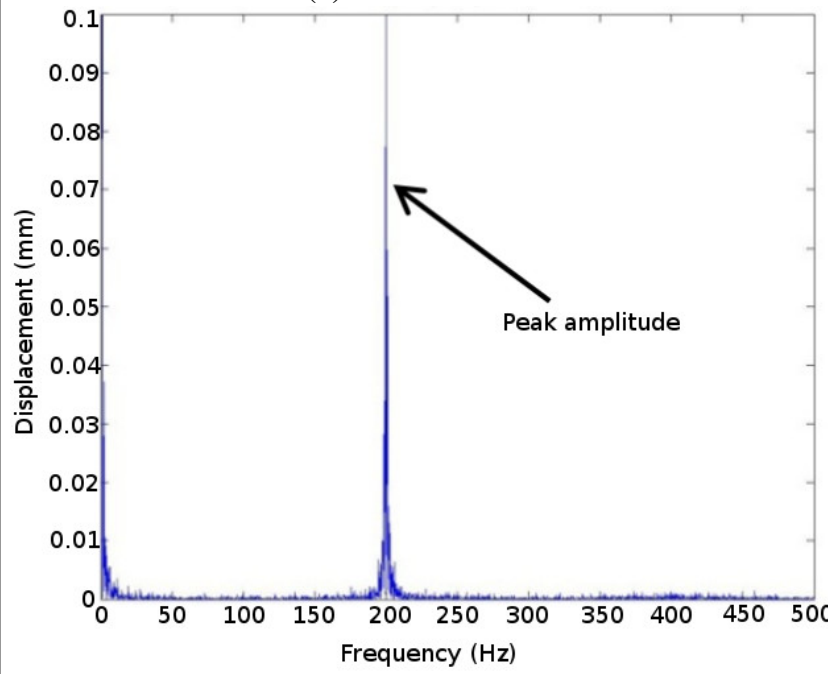

(b) Inboard Pad

Figure 10. Dynamic frequency analysis of both inboard and outboard pads during a stick-slip event.

amined. The Tekscan pressure mapping system (model no: I-Scan) was exploited to measure the contact pressure distribution and the movement of centre of pressure $(\mathrm{CoP})$. A sensor type 5105 was used to measure the pressure distribution between disc/pad interfaces. The sensing area of this particular sensor is $111.8 \mathrm{~mm} \times 111.8 \mathrm{~mm}$ with the spatial resolution of 15.7 sensels per $\mathrm{cm}^{2}$ and the operational pressure range is from 0 to 34 bar.

Contact pressure distribution and centre of pressure (CoP) were measured under various brake pressures for original pads, freshly bedded pads and part-worn pads. Preliminary results indicated that the pressure distribution profile of the original pads and freshly bedded pads were relatively similar to each other. It was therefore decided to compare only freshly bedded pads and part-worn pads. The tests included static pressure measurements with a pressure sensitive film inserted between 
the pad friction face and the disc. This allowed the movement of the centre of pressure to be plotted against different sets of caliper pressures. The graphical images of contact pressure distribution of both the outboard and inboard pad were captured to exhibit the characteristic behaviour of each of the pads. The tests were then compared with the part-worn pads. It has been demonstrated in other research ${ }^{13}$ that it is possible to measure the dynamic centre of pressure during a brake application. However, for this research it was not feasible to insert the pressure sensitive film within the friction material; therefore, only static measurements were possible. It is appreciated that the dynamic centre of pressure (with disc rotation) will differ from the static measurements; however, the static measurements still give a good indication of the centre of pressure movement tendencies.

\subsubsection{Measurement of CoP - Longitudinally}

Bedded pad - At low brake pressure settings, the CoP of the inboard pad was found to be positioned towards a leading offset; however, as the brake pressure was increased, the $\mathrm{CoP}$ tended to move longitudinally towards the centre of the pad. In contrast, the centre of pressure of the outboard pad was found to have a trailing offset and as the caliper pressure was increased, the longitudinal centre of pressure varied only slightly, remaining close to the centre of the pad at all pressures. The results show the longitudinal CoP of both the inboard and outboard pads shifted toward the centre of the pad at higher brake pressure settings. It was clear from the graphs that the longitudinal CoP of the outboard pad tended to have more trailing offset and remained towards the trailing edge of the pad even with the higher caliper pressure settings. However, the centre of pressure of the inboard pad was initially positioned towards a leading offset at low brake pressure, but as the pressure increased, the centre of pressure moved towards the centre of the pad still remaining on the leading side as shown in Fig. 11(a). It was apparent from the experimental results that the inboard pad appeared to carry significantly more load than the outboard pad. Such a situation can lead to possible thermal issues and cross disc thickness temperature gradients. This observation will be the subject of further investigation.

Part-worn pad - The term "part worn" is an attempt to distinguish between newly bedded pads and pads that have experienced earlier temperature cycles where the compound characteristics are changed as the matrix "hardens". It is beyond the scope of this paper to consider measuring changes in material characteristics. The accepted process for measuring compressibility gives different results from company to company, even if the pads are from the same batch and the same test equipment specification is used. The process considers only a sample from the pad and not the pad as a whole. There is no accepted standard to measure the whole of the pad and no accepted standard to measure shear which is so important in stick-slip studies. Because of the many variables that influence friction material characteristics, it was found sufficient at this stage to compare freshly bedded pads to part-worn pads to determine if there was any apparent difference. The authors appreciate the need to have some correlation between "freshly bedded pads" and "part-worn pads" but that has not been the focus of the paper at this juncture. The results show the longitudinal $\mathrm{CoP}$ of both the inboard and outboard pads shifted toward the centre of the pad at higher brake pressure settings. It was clear from the graphs that the longitudinal $\mathrm{CoP}$ of the

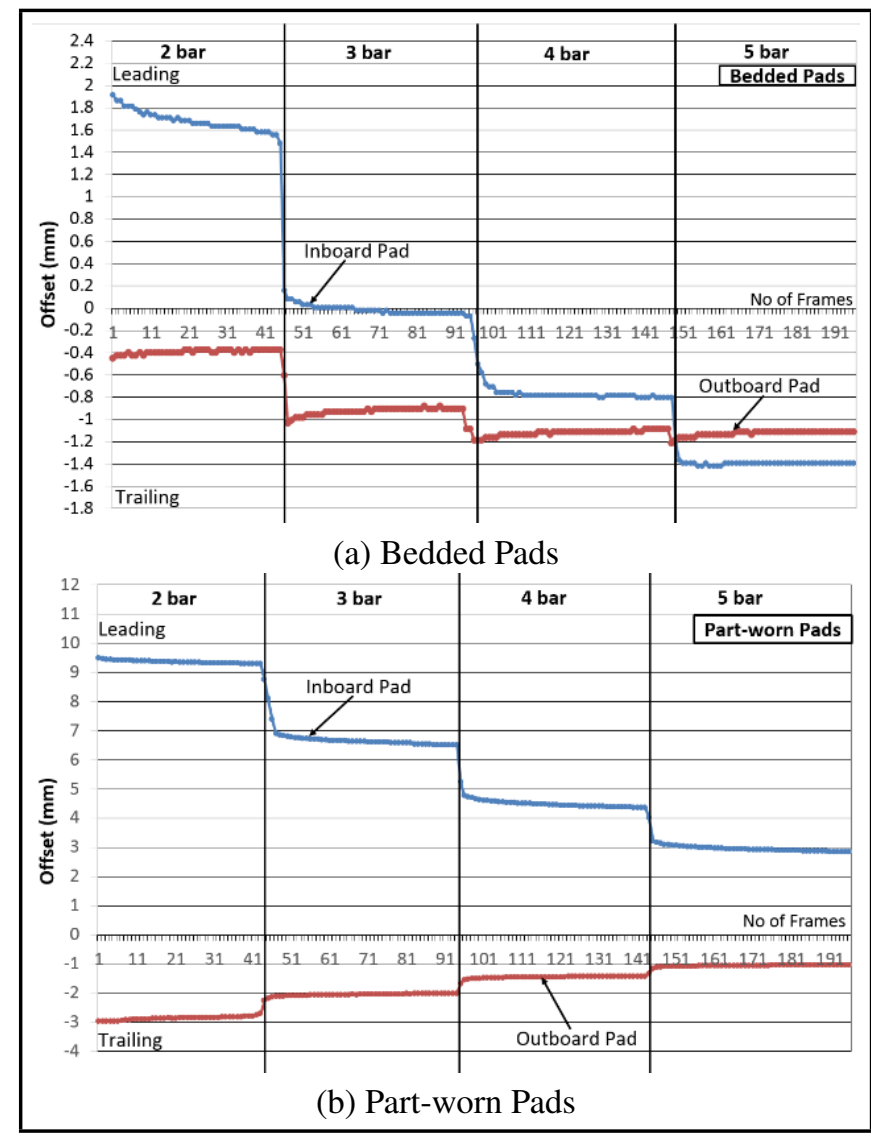

Figure 11. Longitudinal movement of the centre of pressure with varying pressures for bedded (a) and part-worn pads (b).

outboard pad tended to have more trailing offset and remained towards the trailing edge of the pad even with the higher caliper pressure settings. However, the centre of pressure of the inboard pad was initially positioned towards a leading offset at low brake pressure, but as the pressure increased, the centre of pressure moved towards the centre of the pad still remaining on the leading side as shown in Fig. 11(b).

\subsubsection{Measurement of CoP — Radially}

Bedded pad - It was apparent from the results shown in Fig. 12(a) that by increasing the brake pressure, the centre of pressure of the inboard pad moved radially inward towards the centre of the pad, whereas the centre of pressure of the outboard pad moved radially outward.

Part-worn pad - It was observed that by increasing the brake pressure, the centre of pressure of both inboard and outboard pads moved radially inward towards the centre of the pads and centre of pressure shifted towards central to inwards of the radial centre line as exhibited in Fig. 12(b).

\subsubsection{Comparison of bedded and part-worn pads}

The pressure distribution and centre of pressure of both the bedded and part-worn pads were compared to identify the characteristic behaviour of each type of pad. The outboard pad was not of concern as it had a trailing longitudinal centre of pressure therefore making it less prone to generate noise.

However, with regard to the inboard pads, the longitudinal centre of pressure of the part-worn pads tended to have more leading offset compared to the freshly bedded pads as shown in Figs. 11 and 13. It was also noted that even with a higher caliper pressure setting, the centre of pressure of the inboard 


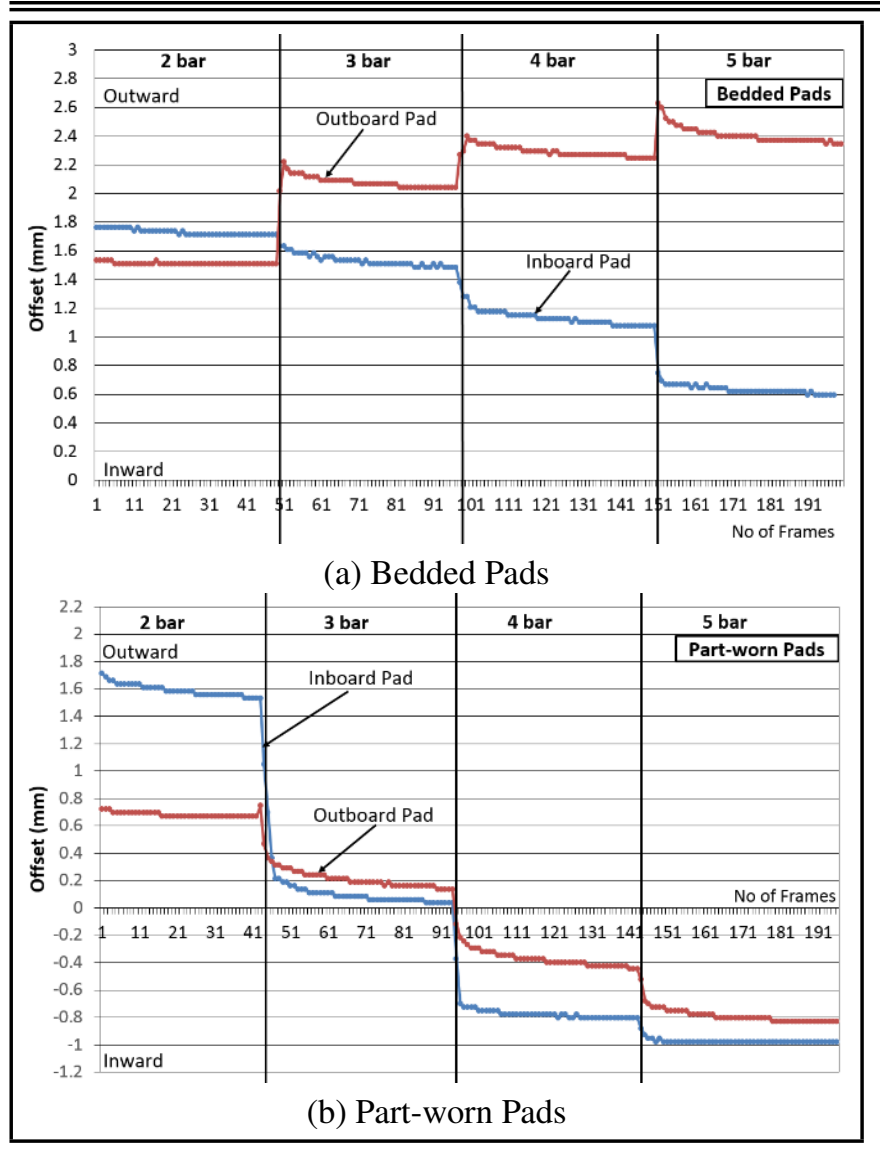

Figure 12. Radial movement of the centre of pressure for bedded (a) and part-worn pads (b).

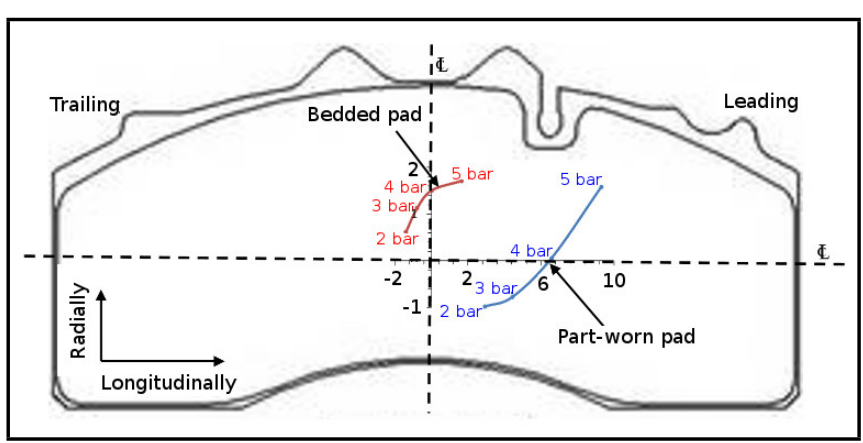

Figure 13. Movement of $\mathrm{CoP}$ with various hydraulic pressures on the actual pad surface (inboard pad).

pad remained towards the leading edge resulting in higher contact area at the leading edge as shown in Fig. 13; this was potentially a cause of instability in the assembly.

\subsection{Effects of Different Parameters on Stick- Slip Vibration}

It was established from the above results that large deformations of the caliper and non-uniform contact between the pads and disc were occurring. It was believed that both of these could be causing, or influencing, the stick-slip motion. As described in Section 1, the tangential stiffness of the brake assembly (typically pads, caliper and anchor bracket) can influence the stick-slip vibration when the sliding velocity is within the critical region where the friction-velocity graph has a negative slope. Therefore, by influencing the stiffness of either the pads or caliper assembly a change may result.
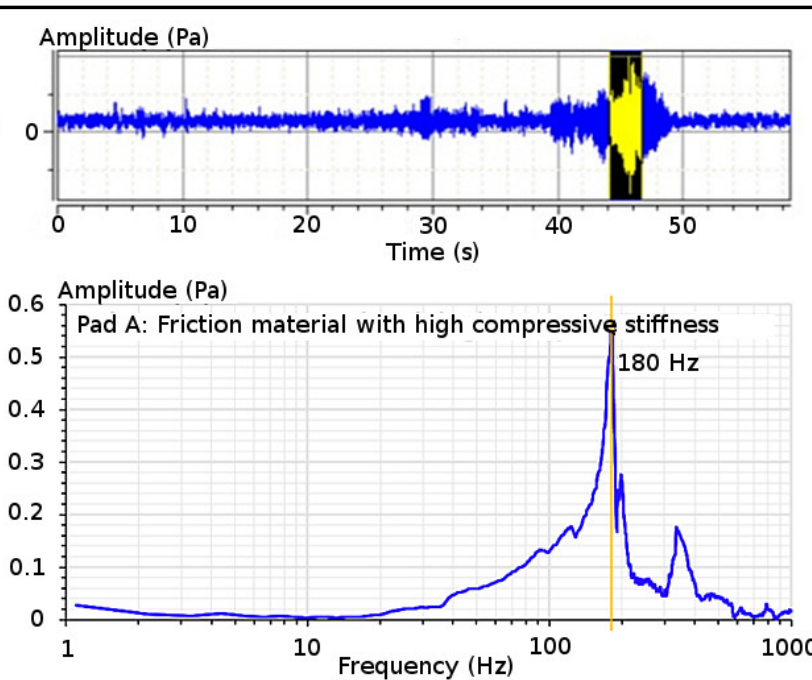

(a) Pad A
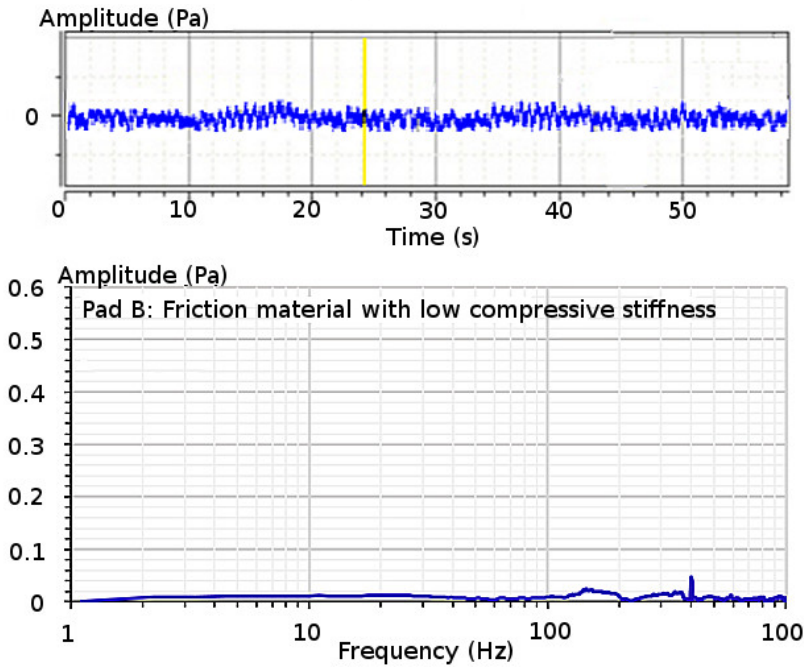

(b) Pad B

Figure 14. Comparison of two sets of pads with different friction materials.

\subsubsection{Effect of different friction material}

Brake pads with different friction materials, which had different compressive stiffnesses, were fitted to observe their effect on the propensity for brake noise. It was established from noise assessment tests as displayed in Figs. 14(a) and (b), that the brake pad with the lower stiffness friction material (Pad B) reduced the occurrence of stick-slip vibration and was therefore less prone to the associated noise as shown in Fig. 14(b). Compressive stiffness of the pads should be as low as possible to promote uniform contact pressure but at the same time high enough to achieve a "good pedal feel" and an optimal brake performance in terms of brake torque capability. This will be subject to further investigation.

\subsection{Discussion of Results}

It was found that the low frequency stick-slip vibration and resultant noise depended on the elastic deformation of the caliper and the friction material of the pad. It was established that the trailing edge of the caliper deformed significantly in the axial direction whereas leading end deformation was almost negligible. This unusual deformation behaviour of the caliper allowed the contact pressure distribution between the disc/pad interfaces to change considerably causing the stick- 
slip phenomenon - the pads were incapable of maintaining a grip on the disc. A large deflection at the trailing edge of the caliper caused the outboard pad to distort with the caliper in the same direction, however, causing the inboard pad to compress more against the disc towards the leading edge resulting in loss of contact with the disc towards the trailing edge of the pad. It was observed that the inboard pad vibrated more vigorously because of the dissimilar contact area towards the leading and trailing edges of the pad. A similar result was also obtained during the noise frequency tests.

The pressure distribution results also corroborated that the centre of pressure of the inboard pad was moving more dynamically, causing instability in the brake system. The disc brake was more prone to noise when the centre of pressure was towards the leading edge of the pad. In order to reduce the intensity of noise within the brake system, the position of the centre of pressure must be towards the trailing edge of the pad. It was observed that noise would be more likely if the centre of pressure moved radially inwards towards the centre of the pad. These findings compared well with the previous work by Fieldhouse, et al., ${ }^{13}$ in which it was reported that the ideal position for the centre of pressure of the pad would be central to trailing, and radially out from the pad centreline. It was observed that in order to ensure consistent disc brake performance, the interface distribution should be cautiously controlled to maintain a uniform pressure distribution along the length of the pad.

It was also observed that part-worn pads tended to generate stick-slip vibration more often compared to freshly bedded pads. This could be due to the fact that the part-worn pad friction material changes during use, thus increasing the elastic compression stiffness of the pads leading to a reduced contact area towards the leading edge.

\section{CONCLUSIONS}

It has been shown that stick-slip vibration depends to a significant extent on the deformation of the caliper, especially towards the leading edge, causing instability in a commercial vehicle brake assembly, and that the caliper mounting and structural geometry should be designed to withstand the stresses generated during dynamic braking. It can also be concluded that uneven contact area of the brake pad can prompt stickslip vibration, the contact area being reduced as the caliper deforms. In order to suppress the stick-slip vibration in a disc brake, the friction material should have a lower compressive stiffness, thus providing more uniform contact between the disc/pad interfaces and maintaining a greater contact area. It is likely that the compression modulus required to prevent stickslip will differ depending upon the type and construction of the brake assembly; however, a study of the effect on different assemblies would provide further useful information. Although it has not been addressed in this study, it is necessary to consider the shear characteristics of the friction compound in future studies.

\section{REFERENCES}

1 Akay, A. Acoustics of friction, Journal of the Acoustical Society of America, 111 (4), 1525-1548, (2002). https://dx.doi.org/10.1121/1.1456514
2 Abdelhamid, M. K. Creep Groan of Disc Brakes, SAE technical paper 951282, (1995). https://dx.doi.org/10.4271/951282

3 Brecht, J., Hoffrichter, W., and Dohle, and A. Mechanisms of brake creep-groan, SAE technical paper 973026, (1997). https://dx.doi.org/10.4271/973026

${ }^{4}$ Crowther, A. R. and Singh, R. Identification and quantification of stick-slip induced brake groan events using experimental and analytical investigations, Noise Control Eng. J., 56 (4), 235-255, (2008). https://dx.doi.org/10.3397/1.2955772

5 Jang, H., Lee, J. S., and Fash, J. W. Compositional effects of the brake friction material on creep groan phenomena, Wear, 251 (1-12), 1477-1483, (2001). https://dx.doi.org/10.1016/s0043-1648(01)00786-4

6 Fuadi, Z., Maegawa, S., Nakano, K., and Adachi, K. Map of low-frequency stick- slip of a creep groan, Proc. IMechE Part J: J. Engineering Tribology, 224 (12), 1235-1246, (2010). https://dx.doi.org/10.1243/13506501jet834

7 Kim, S. S., Hwang, H. J., Shin, M. W., and Jang, H. Friction and vibration of automotive brake pads containing different abrasive particles, Wear, 271 (7-8), 1194- 1202, (2011). https://dx.doi.org/10.1016/j.wear.2011.05.037

8 Xie, M. S., Zhang, G. R., Li, J. H. and Fritsch, R. Brake pad taper wear on brake moan noise, International Journal of Automotive Technology, 15 (4), 565-571, (2014). https://dx.doi.org/10.1007/s12239-014-0059-x

9 Kim, Y. -D., Jeong, U. -C., Kim, J. -S., Seo, J. -H., Park, T. -S., Lee, S. -H., Yoon, J. -M., and Oh, J. -E. Reduction in the moan noise by frequency-response-function-based substructuring and optimization techniques, Proc IMechE Part D: J Automobile Engineering, 229 (11), 1443-1456, (2015). https://dx.doi.org/10.1177/0954407014564690

10 Bettella, M., Harrison, M. F., and Sharp, R. S. Investigation of automotive creep groan noise with a distributed-source excitation technique, Journal of Sound \& Vibration, 255 (3), 531-547, (2002). https://dx.doi.org/10.1006/jsvi.2001.4178

11 Tirovic, M. and Day, A. J. Disc brake interface pressure distributions, Proc IMechE Part D: J Automobile Engineering, 205 (24), 137-146, (1991). https://dx.doi.org/10.1243/pime_proc_1991_205_162_02

12 Kim, J., Lee, C., and Kim, S. Investigation on correlation between groan noise and coefficient of friction with friction material's difference, SAE technical paper 2004-01-0827, (2004). https://dx.doi.org/10.4271/2004-01-0827

13 Fieldhouse, J., Ashraf, N., Talbot, C., and Pasquet, T. Measurement of the dynamic centre of pressure of the disc/pad interface during a braking operation, International Journal of Vehicle Design, 51 (1/2), 73-104, (2009). https://dx.doi.org/10.1504/ijvd.2009.027116 